\title{
First identification of molybdenite in diamond-hosted sulphide inclusions and possible implications for Re-Os dating of diamonds
}

\author{
Lotta I.M. Kemppinen' ${ }^{1}$, Simon C. Kohn' ${ }^{1}$, Ian J. Parkinson' ${ }^{1}$, Galina P. Bulanova ${ }^{1}$, \\ Daniel H. Howell ${ }^{1}$ and Chris B. Smith ${ }^{1}$ \\ ${ }^{1}$ University of Bristol, United Kingdom,lk15127@bristol.ac.uk, simon.kohn@bristol.ac.uk, \\ ian.parkinson@bristol.ac.uk, galina_bulanova@hotmail.com,daniel.howell@bristol.ac.uk \\ chris_b_smith@btopenworld.com
}

\section{Introduction}

Sulphide inclusions in natural diamonds provide information about sulphides originating at depth during reactions involved in diamond growth. Although their role in the formation of diamonds is unclear, sulphides control the highly-siderophile element budget of the mantle and Re-Os isotopic systematics can be applied to syngenetic sulphide inclusions to date diamond growth and related mantle processes (Pearson et al. 1998, Harvey et al. 2016). Sulphide inclusions in diamonds typically have hetereogeneous $\mathrm{Fe}, \mathrm{Ni}$ and $\mathrm{Cu}$ distributions because of mineral unmixing from a former melt or monosulphide solid solution, during their ascent to the surface (Harris 1972, Taylor and Liu 2009). Rosette-shaped fractures which are characteristic of sulphide inclusions, form upon decompression and/or cooling. Here, we report the discovery of a molybdenite phase in sulphide inclusions in eclogitic diamonds from Mir (Yakutia, Russia). Molybdenite is the main host of Re on Earth and its presence in sulphide inclusions and decompression fractures could significantly affect the partitioning of Re inside the inclusions, potentially leading to inaccurate radiometric ages.

\section{Samples and methods}

Sulphide inclusions in 7 Mir eclogitic diamonds have been studied with a Thermo Scientific DXR Raman microscope using 455 and $532 \mathrm{~nm}$ lasers and a 50× LWD objective. The diamonds are colourless and range in size $(3-6 \mathrm{~mm})$ and shape. The samples were previously prepared for sulphide inclusion study at the Diamond and Precious Metal Institute (Siberian Branch RAS, Russia) but still contain many intact inclusions including sulphides, omphacite, pyrope-almandine garnet and coesite (Bulanova et al. 1999). The sulphide inclusions have varying shapes, sizes and decompression fractures (1B).

\section{Raman results}

$$
\text { A }
$$
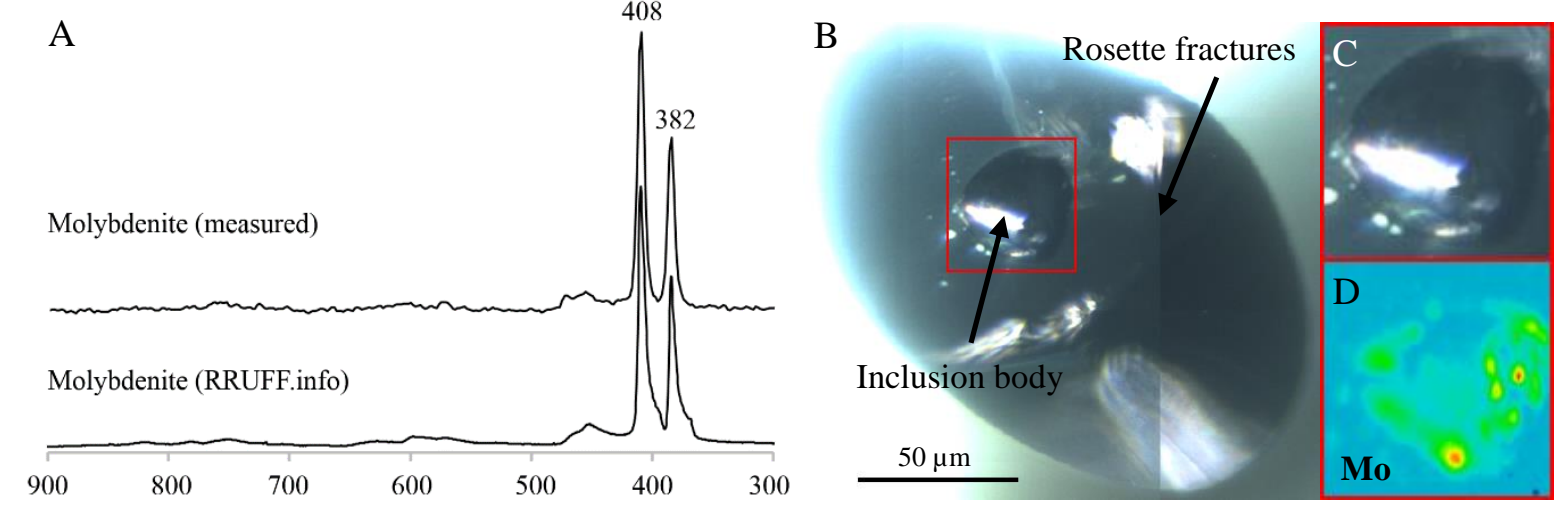

Figure 1: A) Raman spectra of molybdenite measured in a sulphide inclusion compared with the reference spectrum available from the RRUFF database (Lafuente et al. 2015). B) Photomicrograph of an inclusion in a Mir eclogitic diamond containing a sub-euhedral body and rosette-shaped fractures. C) enlargement of the photomicrograph. D) a Raman peak height map shows in red where the molybdenite signal is most intense (yellow and green colours show where the signal is present but weaker). 
Raman suggests molybdenite (Fig. 1A) occurs inside at least 75 sulphide inclusions in 7 diamonds. Raman maps show that molybdenite forms as sub- $\mu \mathrm{m}$ sized disseminations or an irregular rim near the edges of the inclusions (Fig. 1D), and sometimes is concentrated in one point. Molybdenite is commonly found intergrown with, or adjacent to, chalcopyrite and both sometimes seen as a film or in points inside the decompression fractures surrounding the inclusions.

To consider whether the occurrence of molybdenite was restricted to Mir or is a more general phenomenon, we conducted preliminary Raman studies of sulphide inclusions from other localities. We have observed molybdenite in sulphide inclusions in eclogitic diamonds from Argyle (NW Australia) and Dachine (French Guiana), as well as peridotitic diamonds from Murowa (Zimbabwe) and Udachnaya (Sakha Republic, Russia).

\section{Application to Re/Os ages}

The strong partitioning of Re (relative to Os) into molybdenite implies that radiogenic ${ }^{187} \mathrm{Os}$ could remain in the sampled part of the inclusion but some parent ${ }^{187} \mathrm{Re}$ could be "hidden" in inaccessible, and therefore not dissolved molybdenite. The apparent overabundance of ${ }^{187}$ Os relative to ${ }^{187} \mathrm{Re}$ would incorrectly imply that a longer time had elapsed in order to generate the measured ${ }^{187}$ Os concentrations. The details of how Re/Os dates would be affected by missing the molybdenite phase depend on various factors including; a) the abundance of molybdenite in the inclusion, b) the proportion of molybdenite missed (e.g. in decompression fractures) during the extraction of the inclusion, c) the bulk $\operatorname{Re}$ and ${ }^{187} \mathrm{Re} /{ }^{188} \mathrm{Os}$ ratio of the inclusion, d) the method of age determination (i.e. model age or isochron age), e) the timing of molybdenite exsolution (i.e. shortly after trapping of the inclusion, or during exhumation by kimberlite), and f) the partition-coefficient (D) of Re between molybdenite and the residual sulphide inclusion. The batch melting equation was used to explore the behaviour of $\operatorname{Re}$ between molybdenite and coexisting $\mathrm{Fe}-\mathrm{Ni}-\mathrm{Cu}$ sulphides (termed MSS) (Fig. 2A). Published concentrations of $\mathrm{Re}$ in molybdenite relative to $\mathrm{Fe}$ - and $\mathrm{Cu}$-sulphides were used to estimate the partition coefficients used in our calculations (Mathur et al. 2002, Lawley et al. 2013). To estimate how much molybdenite could form from a sulphide melt trapped in diamond, we consider sulphide inclusions trapped as a homogeneous phase with mean molybdenum (Mo) content (ppm) forming molybdenite upon eruption. In our model, the amount of molybdenite present ranges from $10^{-5}-0.005 \mathrm{wt}$. \% of the whole inclusion (larger amounts seem unreasonable requiring > $3000 \mathrm{ppm}$ Mo to be dissolved in the sulphide melt/MSS prior to exsolution).
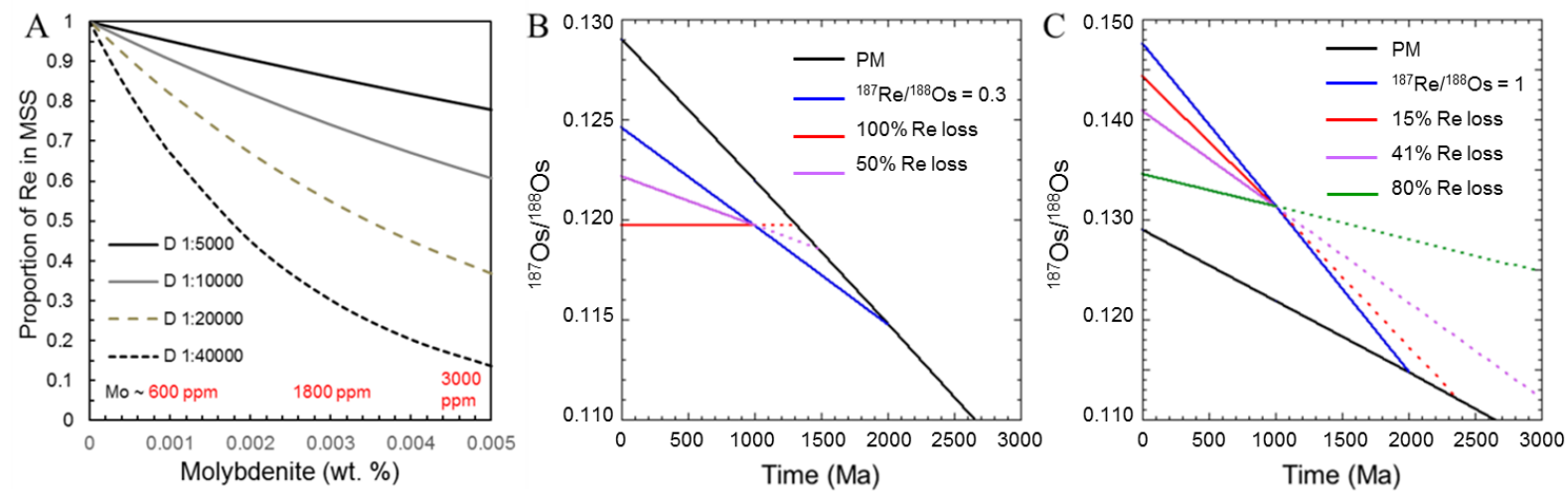

Figure 2: A) The relationship between the amount of molybdenite present (wt.\% and ppm) and the proportion of Re remaining in monosulphide solid solution (MSS) for different partition-coefficient (D) values. B) ${ }^{187} \mathrm{Os}$ evolution diagram shows $2 \mathrm{Ga}$ age sulphide with Re loss (in different proportions) at $1 \mathrm{Ga}$ event for sub-chondritic evolution (relative to the Primitive Mantle PM), and C) supra-chonditric evolution.

To model the effects molybdenite could have on the age systematics of host inclusions, we consider hypothetical sulphide inclusions of sub-chondritic (Fig. 2B) and supra-chondritic (Fig. 2C) Re/Os 
compositions trapped in diamond in molten form at $\sim 2 \mathrm{Ga}$. In both scenarios, Re has segregated in different proportions into molybdenite at $1 \mathrm{Ga}$. Figure $2 \mathrm{~B}$ shows that losing all of the Re from the sampled part of a "sub-chondritic" inclusion would produce a minimum modal age $\left(\mathrm{T}_{\mathrm{RD}}=\mathrm{T}_{\mathrm{MA}}\right)$. 50\% Re loss would produce ages older $\mathrm{T}_{\mathrm{MA}}$ but Re loss $\left(\mathrm{T}_{\mathrm{RD}}\right)$ will always give modal ages. Figure $2 \mathrm{C}$ shows that for a supra-chondritic inclusion, $15 \%$ Re loss would yield an older age $(\sim 2.3 \mathrm{Ga}) .41 \%$ is the maximum loss giving an age the same as the age of the Earth. Losing more Re would produce ages older than the Earth, until the slope becomes parallel with that of the primitive mantle line, before giving future ages (i.e. like the $80 \%$ Re loss curve illustrated in fig. 2C).

\section{Discussion}

Molybdenite occurs at the outermost edge of sulphide inclusions and along thermal decompression fractures, implying that it could be missed when extracting the inclusions from diamonds, prior to dissolution and chemical separations of Re and Os. The implications of this for radiometric dating are obscured by uncertainties about the sub-solidus behaviour of Re and Os between different sulphides, and the timing of sulphide exsolution. However, depending on the Re/Os ratio of the inclusions, and the method used in dating, omitting molybdenite could potentially induce errors on the ages of the inclusions, for example by producing ages older than the Earth or future ages. Although the origin and significance of this molybdenite is still unknown, the presence of molybdenite in inclusions inside both peridotitic and eclogitic diamonds implies that something other than bulk Mo availability (increased by subduction for example) may control molybdenite exsolution. Other influences may also play a role, such as different source materials for sulphide and silicate inclusions or variations in oxygen fugacity. Because diamond inclusions are such valuable samples, we suggest that Raman investigation to identify the presence of molybdenite and its location within a diamond inclusion, should precede Re-Os dating procedures or the use of any other destructive techniques.

\section{References}

Mathur R, Marschik R, Ruiz J, Munizaga F, Leveille RA and Martin W (2002) Age of mineralization of the Candelaria Fe oxide $\mathrm{Cu}-\mathrm{Au}$ deposit and the origin of the Chilean iron belt, based on Re-Os isotopes. Econ Geol 97(1):59-71

Bulanova GP, Shelkov D, Milledge HJ, Hauri EH and Smith CB (1999) Nature of eclogitic diamonds from Yakutian kimberlites: evidence from isotopic composition and chemistry of inclusions. In Proc 7th Int Kimb Conf 57-65

Harris JW (1972) Black material on mineral inclusions and in internal fracture planes in diamond. Contrib Mineral Petrol 35:22-33

Harvey J, Warren JM and Shirey SB (2016) Mantle Sulfides and their Role in Re-Os and Pb Isotope Geochronology. Rev Mineral Geochem 81:579-649

Lafuente B, Downs R T, Yang H and Stone N (2015) The power of databases: the RRUFF project. In: Armbruster T and Danisi RM (eds) Highlights in Mineralogical Crystallography, W. De Gruyter, Berlin, Germany, pp 1-30

Lawley C, Selby D and Imber J (2013) Re-Os molybdenite, pyrite, and chalcopyrite geochronology, lupa goldfield, southwestern Tanzania: tracing metallogenic time scales at midcrustal shear zones hosting orogenic Au deposits. Econ Geol 108(7):1591-1613

Pearson DG, Shirey SB, Harris JW and Carlson RW (1998) Sulphide inclusions in diamonds from the Koffiefontein kimberlite, S Africa: Constraints on diamond ages and mantle Re-Os systematics Earth Planet Sci Lett 160:311-326

Taylor LA and Liu Y (2009) Sulfide inclusions in diamonds: not monosulfide solid solution. Russ Geol Geophys 50:1201-1211 